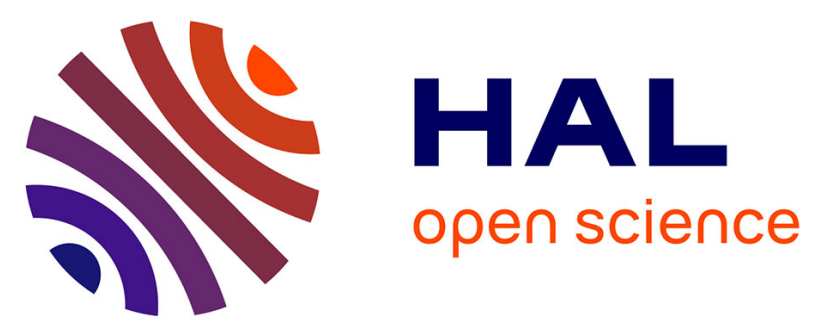

\title{
A fine-scale spatial analysis of fungal communities on tropical tree bark unveils the epiphytic rhizosphere in orchids
}

Remi Petrolli, Conrado Augusto Vieira, Marcin Jakalski, Melissa F Bocayuva, Clément Vallé, Everaldo da Silva Cruz, Marc-andré Selosse, Florent Martos, Maria Catarina M. Kasuya

\section{To cite this version:}

Remi Petrolli, Conrado Augusto Vieira, Marcin Jakalski, Melissa F Bocayuva, Clément Vallé, et al.. A fine-scale spatial analysis of fungal communities on tropical tree bark unveils the epiphytic rhizosphere in orchids. New Phytologist, In press, 10.1111/nph.17459 . hal-03279090

\section{HAL Id: hal-03279090 https://hal.science/hal-03279090}

Submitted on 6 Jul 2021

HAL is a multi-disciplinary open access archive for the deposit and dissemination of scientific research documents, whether they are published or not. The documents may come from teaching and research institutions in France or abroad, or from public or private research centers.
L'archive ouverte pluridisciplinaire HAL, est destinée au dépôt et à la diffusion de documents scientifiques de niveau recherche, publiés ou non, émanant des établissements d'enseignement et de recherche français ou étrangers, des laboratoires publics ou privés. 
1 A fine-scale spatial analysis of fungal communities on tropical tree bark unveils the

3

4 5

REMI PETROLLI ${ }^{1 *}$, CONRADO AUGUSTO VIEIRA ${ }^{1,2^{*}}$, MARCIN JAKALSKI $^{3}$, MELISSA F. BOCAYUVA ${ }^{2}$, CLEMENT VALLE $^{1}$, EVERALDO DA SILVA CRUZ $^{2}$, MARC-ANDRÉ $^{-}$ SELOSSE ${ }^{1,2,3 \S}$, FLORENT MARTOS ${ }^{1 \S}$, MARIA CATARINA M. KASUYA $^{2 \S}$

${ }^{1}$ Institut de Systématique, Évolution, Biodiversité (ISYEB), Muséum national d'Histoire naturelle, CNRS, Sorbonne Université, EPHE, CP 39, 57 rue Cuvier, F-75005 Paris, France ${ }^{2}$ Department of Microbiology, Viçosa Federal University (UFV), P. H. Rolfs street CEP: 36570-900, Viçosa, Minas Gerais, Brazil

${ }^{3}$ University of Gdańsk, Faculty of Biology, ul. Wita Stwosza 59, 80-308 Gdańsk, Poland *These authors contributed equally to this work.

$\S$ These authors supervised equally this work.

\section{Rémi Petrolli (Corresponding author)}

Muséum National d'Histoire Naturelle

UMR 7205, Institut de Systématique, Évolution et Biodiversité (ISYEB),

12 rue Buffon, CP 39, 75005 Paris, France

Email : remi.petrolli@mnhn.fr

6162 words: 842 words (Introduction), 1916 words (M\&M), 1146 words (Results) and 2258 words (Discussion). 5 colored figures, 1 table, and 23 supplementary figures and tables.

\footnotetext{
We declare no conflict of interest regarding this work.
} 


\section{Abstract}

- Approximately $10 \%$ of vascular plants are epiphytes and, even though this has long been ignored in past research, can interact with a variety of fungi, including mycorrhizal ones. However, the structure of fungal communities on bark, as well as their relationship with epiphytic plants, is largely unknown.

- To fill this gap, we conducted environmental metabarcoding of ITS-2 region to understand the spatial structure of fungal communities of the bark of tropical trees, with a focus on epiphytic orchid mycorrhizal fungi, and tested the influence of root proximity.

- For all guilds, including orchid mycorrhizal fungi, fungal communities were more similar when spatially closed on bark, i.e., displayed positive spatial autocorrelation. They also showed distance decay of similarity from epiphytic roots, meaning that their composition on bark increasingly differed, compared to roots, with distance from roots.

- We first showed that all the investigated fungal guilds presented a spatial structure at very small scales. This spatial structure was influenced by the roots of epiphytic plants, suggesting the existence of an epiphytic rhizosphere. Finally, we showed that orchid mycorrhizal fungi were aggregated around them, possibly resulting from a reciprocal influence between the mycorrhizal partners.

\section{Key words}

epiphytism; fungal guilds; metabarcoding; fungal spatial distribution; orchid mycorrhizal fungi;

\section{Tulasnellaceae}




\section{Introduction}

Although globally distributed, microorganisms present a highly variable local richness and a spatial structure at every scale (from centimeters to thousands of kilometers), especially in soils (Green et al., 2004; Green \& Bohannan, 2006). Much of the soil microbial biodiversity appears to be intrinsically linked with plants in the rhizosphere and controls their community structure by monitoring soil-root interactions (Bever et al., 2010). Reciprocally, soil microorganisms that develop nutritional and protective symbioses with roots are especially structured by host presence and diversity (Peay et al., 2013) such as the mycorrhizal fungi that associate with approximately $90 \%$ of the vascular land flora (Van Der Heijden et al., 2015; Brundrett \& Tedersoo, 2018). Fungal metabarcoding studies in soils have shown that the mycorrhizal taxa are not randomly distributed, but exhibit spatial structure at rather fine scales, in temperate as in tropical systems (Anderson et al., 2014; Bahram et al., 2016; Coince et al., 2013; Pickles et al., 2010; Tedersoo et al., 2010; Zhang et al., 2017), i.e., a patchiness due to host distribution, but also other factors such as spore dispersal and community interactions (Hanson et al., 2012). However, the characterization of the underground distribution of soil fungi (mycorrhizal fungi, saprotrophs or pathogens) is complicated by the three-dimensional nature of soils, since differences may exist between soil horizons (Anderson et al., 2014; Bahram et al., 2015).

Unlike soils, tree barks can be easily investigated as their multiple layers can be sampled and sequenced at once, especially on young trees where the bark is usually thin. Thus, young barks can be seen as virtually two-dimensional and are ideal systems for surveying the spatial distribution of fungal communities and mycorrhizal taxa around their epiphytic plant hosts. Indeed, ca. $10 \%$ of vascular plant species root on barks in the tropical wet forests around the globe (Zotz, 2016). These plants have long been considered as essentially non-mycorrhizal in 
such aerial substrates (Lehnert et al., 2017; Brundrett \& Tedersoo, 2018; but see Rowe \& Pringle, 2005) and their fungal partners have thus so far largely been ignored. However, there is now growing interest in the field of epiphytic fungal endophytes which could strongly influence the dynamics of epiphyte plant populations (Leroy et al., 2019). One symbiosis that regularly occurs in the epiphytic habitats is the orchid mycorrhiza (Martos et al., 2012; Herrera et al., 2018; Novotná et al., 2018). Epiphytic orchids, representing no less than $80 \%$ of this hyper-diverse plant family (with over 25000 species (Givnish et al., 2015)), harbor typical hyphal coils within their root cortical cells, which are formed by the same families but different species of saprotrophic basidiomycetes (Dearnaley et al., 2012; Martos et al., 2012; Xing et al., 2019) compared to soil. The fungi are also required for germination of the minute, nutrientpoor orchid seeds (Smith \& Read, 2008). It was therefore hypothesized that the distribution of orchids must be constrained by that of their mycorrhizal fungi (McCormick \& Jacquemyn, 2014; McCormick et al., 2018)

The distribution of orchid mycorrhizal fungi (OMF) has been investigated in soils (Jacquemyn et al., 2014, 2017; McCormick \& Jacquemyn, 2014; McCormick et al., 2016, 2018; Voyron et al., 2017), but only marginally on barks (Kartzinel et al., 2013), perhaps because most studies focus on temperate and Mediterranean ecosystems where orchids are strictly terrestrial. For example, two recent studies (Waud et al., 2016b,a) showed a decline in abundance and similarity composition of OMF with distance from adult orchids, which likely explains the patchy distribution of grassland orchids (Jacquemyn et al., 2007, 2014). Still in grassland habitats, Voyron et al., (2017) found that communities of OMF are more similar in nearby soil, i.e., display spatial autocorrelation (Hanson et al., 2012). As for the epiphytic environment, very little is known on the spatial distribution of mycorrhizal fungi on bark [but see (Izuddin et $a l ., 2019)$ for a first approach]. Similarly, the evolution of their community structure by distance 
to epiphytic host roots is not yet resolved. We can only hypothesize that the low hydro-mineral supply (Yoder et al., 2010; Izuddin et al., 2019) and the particular structure of tree bark (e.g., flaking bark, Rasmussen \& Rasmussen, 2018) can constrain both orchids and fungi, and make the symbiosis even more necessary for the mycorrhizal partners.

Here, we aimed to bridge the gap in knowledge of epiphytic fungal and mycorrhizal fungal communities through an investigation of the fine-scale spatial distribution on trees of (i) all bark fungi, considering (ii) each fungal functional guild (including endophytes), and (iii) the OMF particularly. We investigated a low number of trees in order to design very dense

110 sampling, especially in the vicinity of epiphytic roots, in order to get a first detailed view of the

111 structure of fungal communities on bark and of their relationship to vascular epiphytic plants.

112 We hypothesized that (i) as described in soils, these communities have no random distribution 113 on the bark (patchiness). Due to the ability of many fungi to colonize plant roots, (ii) their

114 distribution should be modulated by the distance to roots of vascular epiphytes. Particularly, 115 (iii) communities of OMF should be aggregated around their orchid hosts.

\section{Materials and Methods}

\subsection{Study area}

121 The study site was situated in a protected fragment of the Atlantic Forest at "Parque Estadual

122 Serra do Brigadeiro" (Rolim \& Ribeiro, 2001), a secondary forest in transition between Dense

123 Rain Forest and Semideciduous Forest (Fávaro, 2012), close to the city of Araponga, Minas

124 Gerais state, Brazil (2043'15.3”'S; 42²8'54.0”W; elevation 1050 m; IEF, 2007). The elevation

125 provides frequent fogs throughout the year, and the humidity is around $80 \%$, even in the dry 
season. The climate of the region is humid subtropical mesothermic, with temperatures ranging from 17 to $23^{\circ} \mathrm{C}$ and annual rainfall averaging $1300 \mathrm{~mm}$ (Rolim \& Ribeiro, 2001). This forest is characterized by medium to large trees, and a high diversity of orchid species, the majority of which are epiphytic (Lana et al., 2018).

\subsection{Bark and root sampling}

Two trees belonging to Siparuna sp. (Siparunaceae; tree 1) and Himathanthus sucuuba

134 (Apocynaceae; tree 2) were selected in February 2015 and February 2016 (95 m away from each other) respectively because they had epiphytic orchids growing on their lower trunk, namely Isochilus linearis and Epidendrum armeniacum. Flexible plastic grids of regular mesh size $(7 \mathrm{~cm})$ were placed around these trunks covering the whole circumference of tree $1(58 \mathrm{~cm}$, Fig. 1) and tree 2 (23 cm, Fig. S1): grid 1 extended from 2 to $2.7 \mathrm{~m}$ above the ground and encompassed five individuals of I. linearis; whereas grid 2 extended from 0.7 to $2.4 \mathrm{~m}$ and encompassed five I. linearis and two E. armeniacum individuals. On each point of the grid, we sampled $100 \mathrm{mg}$ of bark in the center of every pore of the grid using a sterilized scalpel without

142 removing the covering lichens, mosses, or liverworts. The samples thus consisted in small amounts of surface bark (to the cambium, itself not included) and its cryptogamic cover, which

144 was facilitated by the young age of trees and the thinness of these species' bark. We also 145 sampled $3 \mathrm{~mm}$ root sections every $1.5 \mathrm{~cm}$ along each epiphytic orchid root starting from the 146 stem (Fig. 1, S1). Bark was also collected under each root sample. On grid 1, we took additional 147 bark samples in the close vicinity of orchid roots (Fig. 1). This resulted in a total of 482 samples 148 for the two grids (i.e., 167 on grid 1 and 315 on grid 2; Table S1) The rationale behind this 149 dense sampling was that, (i) we expected high turnover of fungal communities at a scale of a 150 few centimeters and (ii) we did not want to miss any important fungi on the bark, especially 
endophytic ones. All samples were frozen at $-20^{\circ} \mathrm{C}$ within few hours in the nearby field

152 laboratory of the Serra do Brigadeiro State Park headquarters for downstream molecular analyses. Two additional thin sections of orchid roots surrounding each sampled piece were

154 collected to check for mycorrhizal fungal colonization on the following day under the 155 microscope and all, without exception, displayed hyphal coils in at least one of each inspection 156 section.

\subsection{High-throughput sequencing of fungal communities}

160 Bark and root samples were kept frozen and manually grinded in liquid nitrogen until a fine

161 powder was obtained. Genomic DNA was extracted from this powder using the NucleoSpin

162 Soil $^{\mathrm{TM}}$ kit (Macherey-Nagel) following manufacturer's instructions and then each isolate was

163 directly set to amplification trials using two primer pairs: ITS86-F/ITS4 (White et al., 1990;

164 Turenne et al., 1999) amplifying the internal transcribed spacer 2 (ITS-2) of ribosomal DNA 165 (Yang et al., 2018) of most fungi, and ITS86-F/ITS4-tul (Taylor \& McCormick, 2008) 166 amplifying the same region in Tulasnellaceae, since this OMF family requires specific primers 167 for amplifying its ribosomal DNA (Martos et al., 2012). High sample multiplexing (up to 576 samples for each primer pair) was allowed through the use of a unique pair of barcoded primers

169 during the PCRs, i.e., 36 forward primers (ITS86-F barcodes 1-36) and 16 reverse primers 170 (ITS4 barcodes 1-16 in fungi-specific, or ITS4-Tul barcodes 17-32 in Tulasnellaceae-specific, 171 PCRs). Each barcode was a unique sequence of 8 bases added to the 5' end of the primer 172 sequence, and the set of 36 barcodes was designed in order to have at least five differences 173 between barcodes.

174 Tagging system negative controls were performed at this step (Hornung et al., 2019; Zinger et 175 al., 2019), i.e., pairs of barcoded primers were intentionally omitted in the final sequencing to 
176 control for cross-contamination. PCR reactions were performed in $25 \mu \mathrm{L}$ containing $0.2 \mathrm{mM}$

177 each dNTP, $0.2 \mathrm{mM}$ each primer, 1 unit AmpliTaq Gold ${ }^{\circledR} 360$ DNA Polymerase (Life

178 Technologies, Carlsbad, CA), 1 X AmpliTaq Buffer supplied with $\mathrm{MgCl}_{2}$ and $1.5 \mu \mathrm{L}$ template

179 DNA, using this program: initial denaturation $10 \mathrm{~min}$ at $95^{\circ} \mathrm{C} ; 30$ cycles of denaturation $30 \mathrm{~s}$ at

$18095^{\circ} \mathrm{C}$, annealing $30 \mathrm{~s}$ at $56.5^{\circ} \mathrm{C}$ (ITS86-F/ITS4) or $55^{\circ} \mathrm{C}$ (ITS86-F/ITS4-tul), and elongation 30s

181 at $72^{\circ} \mathrm{C}$; final elongation $7 \mathrm{~min}$ at $72^{\circ} \mathrm{C}$. Plate designs were randomized in order to avoid

182 possible cross-contamination leading to misinterpretation in subsequent spatial analysis. After

183 visualization on gel, the positive amplicons were purified with NucleoMag® NGS Clean-up

184 and Size Select (Macherey-Nagel, GmbH \& Co KG.), quantified by fluorescence with Qubit ${ }^{\mathrm{TM}}$

185 dsDNA High-Sensitivity (Invitrogen ${ }^{\mathrm{TM}}$ ), and pooled in equimolar ratios prior to library

186 preparation and $2 \times 250 \mathrm{bp}$ paired-end sequencing on an Illumina MiSeq platform at Fasteris

187 (Geneva, Switzerland). Three positive controls (mock community) and three negative controls

188 (ultrapure water) were used per PCR trial (plate), resulting in a total of 36 positive and 36

189 negative controls in total. All of them were added to the amplicon pool for subsequent

190 bioinformatic analysis (Hornung et al., 2019; Zinger et al., 2019). The mock community used

191 in positive controls was a defined mixture of fungal DNAs of known concentration, including

1924 Ascomycota and 21 Tulasnellaceae grown in pure cultures.

193

$194 \quad 2.4$ Sequencing data processing

196 Paired reads were merged using BBMerge (Bushnell et al., 2017) and the resulting reads were

197 demultiplexed using BBDuk (sourceforge.net/projects/bbmap/); mistagging (Zinger et al.,

198 2019) was also controlled but represented $<0.2 \%$ of the reads. The reads were trimmed from

199 their barcode+primer sequences allowing zero discrepancy, filtered for size $>200$ bp and quality

$200 \geq 25$ using CUTADAPT (Martin, 2011); sequences with "Ns" were removed at this step. 
Operational taxonomic units (OTUs) were constructed using the SWARM 3.0 algorithm (Mahé et al., 2015) with a resolution of 5 (Schneider-Maunoury et al., 2018). Chimeras were removed using both the de novo search option of VSEARCH (Rognes et al., 2016) and a reference-based search of UCHIME (Edgar et al., 2011) against the reference dataset v7.2 (Nilsson et al., 2015).

The original (i.e., trimmed) reads were then mapped on the filtered SWARM representative sequences using BLASTN (Altschul et al., 1990) and a 97\% threshold. This step deals with sequences of different size, especially when using two sets of primers amplifying different 208 fragment lengths. OTUs represented by only one sequence (singletons) were removed. The most abundant sequence was chosen as representative of each OTU, and the final taxonomic 210 assignment was performed using assign_taxonomy.py ('blast' assignment method, with default 211 e-value of 0.001) in QIIME 1.9.1 (Caporaso et al., 2010) against UNITE v8.0 ('All eukaryotes'; 212 https://dx.doi.org/10.15156/BIO/786350). Raw sequences are available in Sequence Read 213 Archive (SRA) under the BioProject accession no. PRJNA692353.

Two OTU tables were retrieved for each primer pair and merged into a single OTU table. OTUs 216 were filtered with the DECONTAM package (Davis et al., 2018) using the "frequency" method. 217 We also discarded those found in the negative and positive PCR controls (Hornung et al., 2019), 218 and those of non-fungal origin. Moreover, we ran rarefaction curves using QIIME 1.9.1 219 (Caporaso et al., 2010) (Fig. S2) and then rarefied the OTU table at $10^{3}$ sequences (in order to 220 both maximize the number of samples kept for subsequent analyses and the fungal community 221 read coverage) (McKnight et al., 2019) using the rrarefy function in the VEGAN package of R 222 (Oksanen et al., 2013).

\subsection{Fungal functional guilds}


OTUs found in at least one orchid root sample were considered as endophytes. Among them, those Basidiomycota belonging to Tulasnellaceae, Ceratobasidiaceae (Veldre et al., 2013), Serendipitaceae (Weiß et al., 2016), and Atractiellales (Kottke et al., 2010) were recognized as orchid mycorrhizal fungi (OMF) (Dearnaley et al., 2012). Besides, trophic guilds were assigned 230 to all OTUs using FunGuild (Zanne et al., 2019): we chose to keep those which were either 231 exclusively saprotrophs, symbiotrophs, plant pathogens, or lichenized fungi. As a consequence of this filter, OTUs used for guild analyzes were mainly identified at least at the genus level $(85.3 \%)$ or at the family level $(97.2 \%)$. For the remaining OTUs, guilds provided by FunGuild were validated based on the author's expertise The OMF were kept in a separate category despite their saprotrophic and symbiotrophic ability (Dearnaley et al., 2012; Selosse \& Martos, 2014).

\subsection{Statistical analyses}

All statistical analyses (except Neutral Community Model which are conducted from

241 abundance data) were conducted from presence-absence data because the specific primer pair 242 biased the read counts of Tulasnellaceae relative to other fungi. We tested the effect of sample 243 sources (root or bark, grid 1 or 2) on the composition of fungal communities with 244 PERMANOVA (999 permutations; grids as "strata") using adonis, complemented with a 245 betadisper test as indicated in the corresponding VEGAN package of R (Oksanen et al., 2013).

246 The data were visually assessed by nonmetric multidimensional scaling ordination (NMDS) using metaMDS in VEGAN. Additionally, we tested for each OTU the ecological dispersion

248 from bark to orchid roots using a neutral community model (Sloan et al., 2006) as detailed in 249 Venkataraman et al. (2015) and Burns et al. (2016). Briefly, for each grid, the relationship 250 between the abundance of an endophytic OTU (considering the OTUs shared between bark and 
roots only) on the overall bark and the frequency detection of this OTU in roots was compared to a neutral model. This neutral model was computed using the $n l s M$ function of the MINPACK.LM package of R. The variability of the model was assessed using $95 \%$ binomial proportion confidence interval (Wilson, 1927) using the HMISC package of R and the goodness of fit of the model was assessed using the coefficient of determination $\left(\mathrm{R}^{2}\right)$.

For fine-scale spatial analyses, we then calculated Euclidean distances, preferring the shortest distance between two samples on the cylindrical trunk, and the Jaccard index of ecological similarity using vegdist in VEGAN. Spatial autocorrelation of fungal communities was analyzed on each grid for (i) composition using Mantel in the ECODIST package of R, and (ii) richness using Moran's $I$ in the SPDEP package of R; for the latter, the neighborhood matrix was computed considering a neighboring distance $<10 \mathrm{~cm}$. The significance of Mantel and Moran statistics was assessed by permutational tests (999 replicates). We further tested the spatial structures of single OTUs using the joincount.test in SPDEP.

Finally, we assessed the turnover of bark fungal communities with increasing distance from the roots, for OTU composition (i.e., distance decay of similarity, based on Jaccard index, between root and bark samples) and OTU richness using a generalized linear model ( $\mathrm{glm}$ function in the default package of R) specifying a log-link binomial (Millar et al., 2011) and a negative 270 binomial distribution respectively. As the similarities between samples are not independent of 271 one another, coefficients of the binomial GLM were obtained using a leave-one-out Jackknife 272 procedure as described in (Millar et al., 2011). The significance of the distance decay of 273 similarity was tested using a permutational Mantel test (Spearman method, 9999 permutations; 274 Anderson et al., 2013), while the significance of the distance decay of richness was assessed by 275 ANOVA (F-test). 


\section{Results}

278

\subsection{Roots and bark harbored distinct, but partially overlapping fungal communities}

We retrieved a total of 22554729 reads after the molecular analyses and high-throughput sequencing. The primer pair ITS86-F/ITS4 yielded much more data and diversity (6 823 OTUs, $36477 \pm 31597$ sequences per sample) than the specific ITS86-F/ITS4-tul set of primers (41 OTUs, including 17 Tulasnellaceae, $15589 \pm 11583$ sequences per sample). Eighteen OTUs, including two Tulasnellaceae, were amplified by both sets of primers. Ascomycota from positive controls (mock community) were all retrieved after sequencing while Tulasnellaceae showing no mismatch with IT86-F and ITS4 or ITS4-tul primers were often but not always (56\%) retrieved after sequencing, depending on their DNA quality and/or concentration.

After removing the controls, 3121888 passed our quality (removal of contaminants) and taxonomic filters (fungi only), resulting in a total of 4390 fungal OTUs in the whole dataset 292 (348 samples, Table S1), including Ascomycota (2 670) and Basidiomycota (1 303) mainly, but also Chytridiomycota (23), Mortiellomycota (9), Mucoromycota (7), Rozellomycota (2),

294 Glomeromycota (1) and unidentified fungi (375). Overall, Agaricomycetes (Basidiomycota) 295 were the most abundant (1 782079 sequences; 57.08\%), followed by Dothideomycetes 296 (Ascomycota; 507594 sequences; 16.26\%; Fig. S3, Table S2). The list of all fungal families 297 and genera detected in the dataset is presented in Table S3. Notably, Sebacinales OTUs all 298 belonged to the clade of Serendipitaceae (data not shown; Weiß et al., 2016).

300 Fungal richness (average number of OTUs per sample) was significantly different between bark 
and roots within each grid, i.e., grid 1 (116 \pm 90 in bark, $42 \pm 32$ in roots) and grid $2(125 \pm 63$ in bark, $255 \pm 108$ in roots; $\mathrm{p}<0.001$ in both cases), as well as between roots $(\mathrm{p}<0.001)$ and between bark $(\mathrm{p}=0.0081)$ from the two grids.

304

Total fungal communities were significantly different between both grids (PERMANOVA: $\mathrm{F}=$ 13.91, $\mathrm{R}^{2}=0.047, \mathrm{p}=0.001$, betadisper: $\left.\mathrm{F}=12.69, \mathrm{p}<0.001\right)$, and between roots and bark (PERMANOVA: $\mathrm{F}=4.57, \mathrm{R}^{2}=0.016, \mathrm{p}=0.001$, betadisper: $\mathrm{F}=29.67, \mathrm{p}<0.001$ ), as shown by nested PERMANOVA. Additionally, grids and compartments (root versus bark) clearly segregated in NMDS analyzes (Fig. 2), despite significant heteroscedasticity which has been 310 shown to poorly affect PERMANOVA test (Anderson \& Walsh, 2013). However, 265 (18.8\%) and 1,000 (38.4\%) OTUs were shared between bark and roots in grids 1 and 2, respectively

312 (Table S4). Neutral Community Model (NCM) analyses showed that, on both grid, endophytic 313 fungal communities tended to differ from a neutral dispersal model 'from bark to roots' but 314 were on the contrary largely overrepresented in the root compartment (Fig. S4-5). Only 315 lichenized fungi on grid 2 were unambiguously less overrepresented in roots than other fungi. 316 (Fig. S6). When considering roots only, fungal communities differed between orchid 317 individuals (PERMANOVA: $\mathrm{F}=1.39, \mathrm{R}^{2}=0.148, \mathrm{p}=0.001$, betadisper: $\mathrm{F}=98.47, \mathrm{p}<0.001$ ) 318 and species (PERMANOVA: $\mathrm{F}=1.92, \mathrm{R}^{2}=0.023, \mathrm{p}=0.001$, betadisper: $10.48, \mathrm{p}=0.002$ ), but 319 more strikingly between grids (PERMANOVA: $\mathrm{F}=4.91, \mathrm{R}^{2}=0.058, \mathrm{p}=0.001$, betadisper: $\mathrm{F}$ $320=23.96, \mathrm{p}<0.001$; Fig. S7), with only $237(10.36 \%)$ shared OTUs (Table S4).

322 Among the 31 OMF OTUs that were found, encompassing the four OMF families (see 2.5, Fig. 3), only five OTUs were shared between the two trees after rarefaction (Table S4) and only one 324 OTU (Tulasnellaceae, TUL-1) when considering the roots only (Table S4, S5). However, the 325 sharing of OMF between grids was not statistically different to that of other fungi, meaning that 
the trees harbored different fungal communities overall. On grid 2, where two orchid species co-exist, OMF OTUs belonging to Ceratobasidiaceae (CER-1) and Serendipitaceae (SER-1) were shared between the two species when they were spatially close (Table S5, Fig. S1). Among the OMF found in roots, only 50\% (2/4) and 47\% (7/15) were also retrieved on bark on grid 1 and 2, respectively (Table S4), so that root communities did not appear to be only a subset of adjacent bark communities.

\subsection{All fungal communities were spatially structured}

All functional guilds, except lichenized fungi on grid 1 and symbiotrophs on both grids, showed significant spatial autocorrelation of OTU composition (Mantel test; Table 1). Among the different guilds, OMF on grid 2 showed the largest distance of positive spatial autocorrelation over approx. $30 \mathrm{~cm}$ (Fig. 4). The whole fungal community, as well as endophytes, also showed positive spatial autocorrelation over approx. $15 \mathrm{~cm}$ and $18 \mathrm{~cm}$ on grid 1 and 2, respectively. For the other guilds, i.e., lichenized fungi, plant pathogens, saprotrophs, and symbiotrophs, spatial autocorrelation was more significant on grid 2, with positive autocorrelation between 0 and 10 -

$34220 \mathrm{~cm}$, compared to grid 1 where it occurred within the first $10 \mathrm{~cm}$ only. The mean Jaccard index for adjacent points separated by $14 \mathrm{~cm}$ tended to be higher vertically than horizontally

344 (comparison possible on grid 1 only; Fig. S8), but due to large variation in the values the difference was not statistically supported.

Regarding spatial autocorrelation of OTU richness, all fungal guilds, except symbiotrophs on grid 1, showed a significant autocorrelation (Moran's I; Table S7). OMF harbored the largest distance of positive autocorrelation on both grids $(30 \mathrm{~cm})$. 
Spatial autocorrelation of single OTUs showed that only OMF on grid 2 tend to be more 352 frequently spatially clustered than other fungi (Table S6). OMF families showed vertical stratification on grid 2 that covered a greater height on the tree $(1.7 \mathrm{~m})$, whereas this pattern was not obvious on grid 1 (covering 0.7 m only; Fig. S9).

\subsection{Epiphytic roots influenced all fungal communities}

The Jaccard similarity between roots and bark fungal compositions significantly decreased with increasing distance from the roots for the whole fungal community on both grids (Fig. 5). This was also observed for endophytes on both grids, for non-OMF symbiotrophs on grid 1 only, and for OMF, plant pathogens and saprotrophs on grid 2 only (Table 1, Fig. 5; see also Fig. S10 and Table S8 for details). The distance decay of bark fungal richness showed contrasting results with either non-significant or opposite results between grids (Fig. S12-14, Table S9).

The evolution of density (i.e., spatial density based on occurrence data) of OMF on bark at a distance from colonized roots showed that they were spatially distributed in the close vicinity of the roots on both grids, but contrasting spatial structures were detected between OMF families on grid 2 (with Tulasnellaceae tending to picking at a longer distance from roots; Fig.

S11). However, by comparing the density distribution of OMF versus endophytes (distance

370 from roots beyond which $80 \%$ of the occurrences of a given OTU are limited), the OMF were 371 not statistically closer to roots than other endophytes (Wilcox tests, $\mathrm{W}=370, \mathrm{p}=0.423$ and $\mathrm{W}$ $372=1142, \mathrm{p}=0.397$ for grid 1 and 2 , respectively).

\section{Discussion}




\subsection{Features of bark fungal communities compared to the soil's}

377

378

379

380

381

382

383

384

385

386

387

The majority of fungal OTUs identified on the investigated tree barks belonged to Ascomycota (61\%) and Basidiomycota (30\%), even if the latter were the most abundant in reads. Other phyla that are usually associated with plants were largely missing in our dataset, such as arbuscular mycorrhizal fungi of the Glomeromycotina division (Spatafora et al., 2017). These fungi poorly amplify with ITS primers (Berruti et al., 2017) and, according to some observational studies (Lehnert et al., 2017), they are less represented (but not absent, see for instance Rowe \& Pringle, 2005) in epiphytic environments than in soils. Conversely, saprotrophic fungi are particularly expected on barks, including the ones known to be symbiotically associated with epiphytic orchids (Kottke et al., 2010; Martos et al., 2012; Herrera et al., 2018; Novotná et al., 2018). It is noteworthy that Tulasnellaceae were broadly retrieved from barks and roots on both trees, which shows the relevance of using specific primers (Tedersoo et al., 2015), even though we cannot exclude that some Tulasnella species did not amplified with these primers.

Fungal metabarcoding has long been carried out in soils and in soil-dwelling plant roots (Schmidt et al., 2013). Soils are complex three-dimensional environments where fungal species and functional groups occupy different horizons (Anderson et al., 2014; Bahram et al., 2015), and where mycorrhizal fungi may not be easily found outside the rhizosphere (Egidi et al., 2018), perhaps due to insufficiently deep investigations. Conversely, bark, especially when thin, offers a nearly two-dimensional environment suitable for exhaustive sampling of microbial species in space and time. While bark has been commonly studied in the context of diseases (e.g. Arrigoni et al., 2020), it has only very recently been regarded as a niche for other fungal guilds (Izuddin et al., 2019; Eskov et al., 2020). 
Here, the fungal communities growing on two trees were clearly distinct, both on the bark and in the roots of epiphytes (Fig. 2, S7). Although our sampling was done to characterize fungal diversity within rather than between trees, we can expect that the structure of epiphytic fungal communities is very complex (Kembel \& Mueller, 2014; Vacher et al., 2016) and far from understood. In both cases, they encompassed much more diverse guilds than the expected saprotrophic and lichenized fungi, showing the complexity of fungal communities as well as the presence in the environment of endophytic and symbiotrophic fungi. Furthermore, 377 fungal OTUs $(8.6 \%)$ could not be identified at a lower taxonomic rank, suggesting that a high and previously unknown fungal diversity exists in such a tropical environment (Cevallos et al., 410 2018).

411 As we chose to work on young trees, the thinness of their bark did not allow us to test for a 412 possible differentiation of the fungal communities throughout the bark layers (e.g., inner versus 413 outer bark) but future studies could focus on this question using older trees with more 414 differentiated barks. However, this thinness allowed us to exhaustively sample fungal 415 communities at a given position. Whether these communities are spatially structured or are 416 either homogeneously or randomly distributed remained an open question, which we 417 investigated in this study.

\subsection{Most OTUs tend to have an endophytic niche on bark}

In soils, there is growing evidence that fungal communities are spatially structured (Blaalid et al., 2012; Kadowaki et al., 2014; Bahram et al., 2016). In our study, total and endophytic communities showed similar and strong spatial turnover on bark (Fig. 4, Table 1). This suggests that there is no difference between fungi able to colonize living roots and those which are not.

425 This may be because most of these fungi regarded as endophytes only colonize roots 
superficially (e.g. in orchid velamen; Herrera et al., 2010) without any functional interaction with the plants; yet many endophytic fungi are likely to extend away from plant tissues and have a partially free-living lifestyle (i.e., not into plant tissues; Selosse et al., 2018). In our study, most of the fungi were found as endophytes $(34.63 \%$ and $78.25 \%$ for grids 1 and 2 , respectively; Table S4). These results reveal that on bark much of the fungal community is able to colonize epiphytic roots, probably because it contains more carbon than the oligotrophic surrounding bark. Accordingly, saprotrophs and plant pathogens (despite non-significantly for the latter) tended to be slightly more present in roots than the rest of the community. On the other hand, lichenized fungi, which can acquire their own carbon through photosynthesis, were less present in roots than other fungi (Table S4).

Neutral community model analyses revealed that endophytes tended to be more frequent in roots than expected by neutral dispersal processes (Fig. S4), which may suggest that root colonization by endophytic fungi is not passive but is rather actively built by hyphal foraging. Interestingly, lichenized fungi on grid 2 tended to be less frequent in roots than expected by neutral dispersal processes (Fig. S6), suggesting that some fungi colonize (or contaminate) roots accidentally. However, contrary to air dispersal in the context of which this model was initially applied (Venkataraman et al., 2015), fungi may rather disperse through hyphae growth (not sporulation) at the small studied scales. Thus, the filtering of fungal communities by the root compartment, although expected, may reflect the abundance of these fungi on adjacent bark. The sampling procedure applied here successfully allowed us to investigate the very fine-scale spatial structure of fungal guilds on the bark at proximity from epiphytic roots.

\subsection{All fungal communities harbor intrinsic spatial structures}

All trophic guilds harbored spatial structures at least on one tree (Fig. 4). Consistently with 
previous results on soil communities (Bahram et al., 2016; Voyron et al., 2017), OMF (despite their low statistical power due to the limited number of OTUs), saprotrophs and plant pathogens were the most spatially structured communities, as shown by Mantel (Table 1, Fig. 4) and Moran (Table S7) tests, perhaps because they exploit resources that are more localized than, e.g. lichenized fungi. As bark trees are subjected to water runoff, one could expect that fungal communities would be more similar vertically than horizontally: this trend was observed, but not statistically supported on grid 1 (Fig. S8). Yet, this analysis was limited by (i) the low diameter of trunks, which limits horizontal measurements (especially on grid 2), and a limited vertical range. Future sampling may investigate a possible axis-dependence of epiphytic fungal communities.

Mycorrhizal fungi are particularly known to display spatial structures (Bahram et al., 2015), for example in ectomycorrhizal (Anderson et al., 2014; Coince et al., 2013; Pickles et al., 2010; Tedersoo et al., 2010), arbuscular (Whitcomb \& Stutz, 2007), ericoid (Toju et al., 2016) or orchid mycorrhizal fungi (Voyron et al., 2017). OMF from grassland soils display spatial 466 autocorrelation up to several meters (Voyron et al., 2017), whereas in our study spatial 467 autocorrelation was limited to a few tens of centimeters (Fig. 4). Although a weak spatial structure is not excluded in soil (Oja et al., 2016), this suggests that epiphytic OMF (or perhaps epiphytic fungi as a whole) experience stronger competition for space on the limited bark surface and thus are more segregated than in soils (Lekberg et al., 2007; Mujic et al., 2016). A 471 non-exclusive explanation may be the fact that the stressing and oligotrophic epiphytic environment for the plant limits the availability of carbohydrates and, from there, the foraging ability of the mycorrhizal mycelia. Alternatively, the turnover of the bark substrate by radial

474 growth, leading to flaking bark (Rasmussen \& Rasmussen, 2018), could also disturb microbial 475 communities, preventing them from spreading throughout the bark surface. 
477 In a recent study, Izuddin et al., (2019) showed that fungal communities vary between 478 microsites (stem/branch/fork) on tropical trees. Our study highlights the fact that even without any apparent heterogeneity of substrate, bark fungal communities have a spatial structure and are neither randomly nor homogeneously distributed. As discussed below, vascular epiphytes, like orchids, also influence the diversity and spatial structure of fungal communities. Barks devoid of epiphytes would thus be of interest to compare the composition and spatial structure of fungal communities without epiphytic roots. Even though trees devoid of any epiphytes can be scarce in tropical rainforests (and often associated with altered habitat), we encourage such investigations for future studies as we do not exclude that contrasting patterns might be found. Here, as we tested the influence of these epiphytes on fungal communities, we chose trees colonized by orchids and showed for the first time that they can shape epiphytic fungal communities.

\subsection{Roots influence all fungal communities in the epiphytic rhizosphere}

Roots are generally colonized by numerous fungi which positively or negatively interact with the plants, e.g., mycorrhizal fungi or fungal pathogens. It can thus be hypothesized that these fungal communities are influenced by the presence of roots (Goldmann et al., 2016; Waud et al., 2016a; Zhang et al., 2017), and vice versa. For instance, it has been shown that saprotrophic, pathotrophic and symbiotrophic fungi were more abundant near the roots in soils (Zhang et al.,

497 2017). Our analyses of richness confirmed this tendency on grid 2 only (Fig. S12 and S14), 498 showing that the distance decay of richness at a distance from roots is dependent upon the 499 studied environments.

500 However, all the fungal guilds except lichenized fungi (see also section 4.2) were influenced 
by the presence of epiphytic roots, at least on one grid. Thus, this significant decay of fungal

502

503

504

505

506

507

508

509

510

511

512

513

514

515

516

517

518

519

520

521

522

523

524

525 community similarity with distance from the roots (Fig. 5, S10, Table S8) does suggest the presence of an epiphytic 'rhizosphere' similar to that classically described in soils. The mechanisms of this rhizosphere influence may differ from one guild to another. For instance, while the OMF should get direct or indirect nutrient and/or protection benefits from the orchid roots (Dearnaley et al., 2012), plant pathogenic fungi should be attracted by the living plants (Morris et al., 1998) and saprotrophic fungi should benefit from root exudates (Sun \& Fries, 1992).

For OMF particularly, the strong decay of similarity observed on grid 2 (Waud et al., 2016a), with short halving distance (Table S8), as well as the quasi absence of OMF at a distance higher than $60 \mathrm{~cm}$ from colonized roots (Fig. S11), suggests that the roots but also their close vicinity act as their main ecological niche (Dearnaley et al., 2012). Although the latter observation and conclusion are often not reported from OMF analyses in soil (Egidi et al., 2018), this may be due to problems of vertical depth of sampling which are alleviated by the thinness of the investigated bark environment.

\subsection{Fungal communities could modulate epiphytic plant population dynamics}

The clustered structure of the epiphytic fungal communities and the existence of an epiphytic root rhizosphere, although the two are intrinsically linked, should strongly influence plant establishment and dynamics. For orchids especially, whose seeds lack reserves and depend on OMF for germination (Dearnaley et al., 2012), it is likely that the distribution of plants may be controlled by OMF distribution (McCormick \& Jacquemyn, 2014; but see a balanced view in Kartzinel et al., 2013).

Here, the OMF were more spatially clustered than any other fungi (Table S6), reflected in the 
vertical stratification on grid 2 (Fig. S9), which suggests that they could strongly constrain orchid seed germination. In soil, it has also been proposed that the patchiness of orchid individuals (Jacquemyn et al., 2007) could be due to that of their mycorrhizal partners (Jacquemyn et al., 2012). Additionally, plant pathogens should also be involved in the

530 establishment of epiphytic plants by modulating the probability of a seedling to establish 531 (Sarmiento et al., 2017). In the future, experimental approaches coupled to metabarcoding may investigate, again with ease as the system is nearly two-dimensional, whether epiphytic orchid seed germination can be predicted from the fungal community at the site of seed deposition

534 (Kartzinel et al., 2013).

\subsection{Conclusion and perspectives}

While metabarcoding studies are increasingly used to describe microbial communities and their spatial structure (Schmidt et al., 2013), epiphytic habitats of tropical environments have been

540 largely overlooked in such research (McCormick et al., 2018). We show for the first time that 541 the fungi and their trophic guilds, in accordance with our first hypothesis, are spatially

542 structured on barks colonized by vascular epiphytes, and that this structure is influenced by the 543 presence of their roots. We thus suggest that a rhizosphere effect also exists for epiphytic plants, 544 and particularly for OMF fungi, confirming our second and third hypotheses, respectively. 545 Additionally, some fungi, including OMF or pathogens, could also influence the presence of 546 the orchid roots (e.g., through seed germination), and the mechanisms behind this epiphytic 547 rhizosphere are thus yet to be explored.

548 Since, although the two tree species were colonized by distinct fungal communities, results 549 were consistent between them, we expect that the observed features can be viewed as default 550 expectations for other bark fungal communities. Yet, future investigations in other epiphytic 
environments, especially environments colonized by epiphytes with arbuscular mycorrhizal fungi, are needed to test this hypothesis and add further relief to the study of epiphytic fungal communities and their interactions with plants.

554 In this study, we observed a vertical niche differentiation for OMF communities, but not for 555 other fungal guilds, probably because our sampling design was not appropriate to investigate 556 such vertical gradients. Yet, a possible trend for lower vertical than horizontal structure was 557 observed. As both biotic (e.g. interspecific competition) and abiotic (e.g. water runoff) factors should influence vertical niche segregation, future studies should focus on bark microbial communities of higher forest trees (Izuno et al., 2016) and their role as potential drivers of

560 epiphytic plant population structure and dynamics.

\section{Acknowledgments}

563 We are very grateful for the financial support by Brazilian Institutions: Conselho Nacional de

564 Desenvolvimento Científico e Tecnológico (CNPq), Coordenação de Aperfeiçoamento de

565 Pessoal de Nível Superior - Brasil (CAPES - Finance Code 001), and Fundação de Amparo à

566 Pesquisa do Estado de Minas Gerais (FAPEMIG). FM was funded by the Agence Nationale de 567 la Recherche (ANR-19-CE02-0002). The authors thank the Service de Systématique 568 Moléculaire (UMS2700 MNHN/CNRS) for access to its facilities, David Marsh for English 569 corrections and Tomas Gomes Reis Veloso for help in sampling. They also acknowledge the 570 administration and scientific staff of the Instituto Estadual de Floresta of the State of Minas

571 Gerais and Serra do Brigadeiro State Park for their provision of facilities and for permission 572 (license number 066/2016) to conduct exploratory surveys in their protected areas. Finally, the 573 authors thank the anonymous referees as well as the editor for their relevant remarks on the 574 manuscript.

\section{Conflict of Interest}


We declare no conflict of interest regarding this work.

\section{Author Contributions}

580

MAS and MCMK designed the study. CAV, MFB and EDSV performed the sampling and the molecular analyses. RP, FM, MJ and CV analyzed the data and wrote the manuscript which was edited by all co-authors.

584

585

\section{Data Accessibility}

Raw sequences are available in Sequence Read Archive (SRA) under the BioProject accession no. PRJNA692353.

The bioinformatic pipeline is provided in the GitHub page of the corresponding author (https://github.com/PetrolliR/MetaBarkCoding.git). Authors can provide initial table and 591 metadata upon reasonable request.

\section{References}

Altschul SF, Gish W, Miller W, Myers EW, Lipman DJ. 1990. Basic local alignment search tool. Journal of Molecular Biology 215: 403-410.

598 Anderson IC, Genney DR, Alexander IJ. 2014. Fine-scale diversity and distribution of 599 ectomycorrhizal fungal mycelium in a Scots pine forest. New Phytologist 201: 1423-1430.

600 Anderson MJ, Tolimieri N, Millar RB. 2013. Beta Diversity of Demersal Fish Assemblages 601 in the North-Eastern Pacific: Interactions of Latitude and Depth. PLOS ONE 8: 1-15.

602 Anderson MJ, Walsh DCI. 2013. PERMANOVA, ANOSIM, and the Mantel test in the face 603 of heterogeneous dispersions: What null hypothesis are you testing? Ecological Monographs 604 83: 557-574.

605 Arrigoni E, Albanese D, Longa CMO, Angeli D, Donati C, Ioriatti C, Pertot I, Perazzolli 
M. 2020. Tissue age, orchard location and disease management influence the composition of fungal and bacterial communities present on the bark of apple trees. Environmental Microbiology 22: 2080-2093.

609 Bahram M, Kohout P, Anslan S, Harend H, Abarenkov K, Tedersoo L. 2016. Stochastic 610 distribution of small soil eukaryotes resulting from high dispersal and drift in a local 611 environment. ISME Journal 10: 885-896.

612 Bahram M, Peay KG, Tedersoo L. 2015. Local-scale biogeography and spatiotemporal 613 variability in communities of mycorrhizal fungi. New Phytologist 205: 1454-1463.

614 Berruti A, Desirò A, Visentin S, Zecca O, Bonfante P. 2017. ITS fungal barcoding primers 615 versus $18 \mathrm{~S}$ AMF-specific primers reveal similar AMF-based diversity patterns in roots and 616 soils of three mountain vineyards. Environmental Microbiology Reports 9: 658-667.

617 Bever JD, Dickie IA, Facelli E, Facelli JM, Klironomos J, Moora M, Rillig MC, Stock 618 WD, Tibbett M, Zobel M. 2010. Rooting theories of plant community ecology in microbial 619 interactions. Trends in Ecology and Evolution 25: 468-478.

620 Blaalid R, Carlsen T, Kumar S, Halvorsen R, Ugland KI, Fontana G, Kauserud H. 2012.

621 Changes in the root-associated fungal communities along a primary succession gradient 622 analysed by 454 pyrosequencing. Molecular Ecology 21: 1897-1908.

623 Brundrett MC, Tedersoo L. 2018. Evolutionary history of mycorrhizal symbioses and 624 global host plant diversity. New Phytologist 220: 1108-1115.

625 Burns AR, Stephens WZ, Stagaman K, Wong S, Rawls JF, Guillemin K, Bohannan 626 BJM. 2016. Contribution of neutral processes to the assembly of gut microbial communities 627 in the zebrafish over host development. ISME Journal 10: 655-664.

628 Bushnell B, Rood J, Singer E. 2017. BBMerge - Accurate paired shotgun read merging via 629 overlap. PLoS ONE 12: 1-15.

630 Caporaso G, Kuczynski J, Stombaugh J, Bittinger K, Bushman FD, Costello EK, Fierer 631 N, Pena AG, Goodrich JK, Gordon JI, et al. 2010. QIIME allows analysis of high632 throughput community sequencing data. Nat Methods 7: 335-336.

633 Cevallos S, Herrera P, Sánchez-Rodríguez A, Declerck S, Suárez JP. 2018. Untangling 634 factors that drive community composition of root associated fungal endophytes of Neotropical 635 epiphytic orchids. Fungal Ecology 34: 67-75.

636 Coince A, Caël O, Bach C, Lengellé J, Cruaud C, Gavory F, Morin E, Murat C, Marçais 637 B, Buée M. 2013. Below-ground fine-scale distribution and soil versus fine root detection of 638 fungal and soil oomycete communities in a French beech forest. Fungal Ecology 6: 223-235. 639 Davis NM, Proctor DM, Holmes SP, Relman DA, Callahan BJ. 2018. Simple statistical 
640 identification and removal of contaminant sequences in marker-gene and metagenomics data.

641 Microbiome 6: 1-14.

642 Dearnaley JDW, Martos F, Selosse MA. 2012. Orchid Mycorrhizas : Molecular Ecology,

643 Physiology, Evolution and Conservation Aspects. In: Fungal Associations, 2nd Edition The

644 Mycota IX. B. Hock (Ed.). Springer Berlin Heidelberg, Germany, 207-230.

645 Edgar RC, Haas BJ, Clemente JC, Quince C, Knight R. 2011. UCHIME improves

646 sensitivity and speed of chimera detection. Bioinformatics 27: 2194-2200.

647 Egidi E, May TW, Franks AE. 2018. Seeking the needle in the haystack: Undetectability of 648 mycorrhizal fungi outside of the plant rhizosphere associated with an endangered Australian 649 orchid. Fungal Ecology 33: 13-23.

650 Eskov AK, Voronina EY, Tedersoo L, Tiunov A V., Manh V, Prilepsky NG, Antipina 651 VA, Elumeeva TG, Abakumov E V., Onipchenko VG. 2020. Orchid epiphytes do not 652 receive organic substances from living trees through fungi. Mycorrhiza 30: 697-704.

653 Fávaro LB. 2012. Estudo ecológico e econômico da palmeira Juçara ( Euterpe edulis Mart.) 654 no entorno do Parque Estadual Serra do Brigadeiro (PESB ), MG.

655 Givnish TJ, Spalink D, Ames M, Lyon SP, Hunter SJ, Zuluaga A, Iles WJD, Clements 656 MA, Arroyo MTK, Leebens-Mack J, et al. 2015. Orchid phylogenomics and multiple 657 drivers of their extraordinary diversification. Proc. R. Soc. B 282: 20151553.

658 Goldmann K, Schröter K, Pena R, Schöning I, Schrumpf M, Buscot F, Polle A, Wubet 659 T. 2016. Divergent habitat filtering of root and soil fungal communities in temperate beech 660 forests. Scientific Reports 6: 1-10.

661 Green J, Bohannan BJM. 2006. Spatial scaling of microbial biodiversity. Trends in Ecology 662 and Evolution 21: 501-507.

663 Green J, Holmes A, Westoby M, Oliver I, Briscoe D, Dangerfield M, Gillings M, Beattie 664 A. 2004. Spatial scaling of microbial diversity. Nature 432: 747-750.

665 Hanson CA, Fuhrman JA, Horner-Devine MC, Martiny JBH. 2012. Beyond 666 biogeographic patterns: Processes shaping the microbial landscape. Nature Reviews 667 Microbiology 10: 497-506.

668 Van Der Heijden MGA, Martin FM, Selosse MA, Sanders IR. 2015. Mycorrhizal ecology 669 and evolution: The past, the present, and the future. New Phytologist 205: 1406-1423.

670 Herrera P, Suárez JP, Kottke I. 2010. Orchids keep the ascomycetes outside: a highly 671 diverse group of ascomycetes colonizing the velamen of epiphytic orchids from a tropical 672 mountain rainforest in Southern Ecuador. Mycology 1: 262-268.

673 Herrera P, Suárez JP, Kottke I, Méndez M, Molina MC, Méndez M, Suárez JP. 2018. 
674 Generalism in the interaction of Tulasnellaceae mycobionts with orchids characterizes a 675 biodiversity hotspot in the tropical Andes of Southern Ecuador. Mycoscience 59: 38-48.

676 Hornung BVH, Zwittink RD, Kuijper EJ. 2019. Issues and current standards of controls in 677 microbiome research. FEMS Microbiology Ecology 95: 1-7.

678 Izuddin M, Srivathsan A, Lee AL, Yam TW, Webb EL. 2019. Availability of orchid 679 mycorrhizal fungi on roadside trees in a tropical urban landscape. Scientific Reports 9: 1-12.

680 Izuno A, Kanzaki M, Artchawakom T, Wachrinrat C, Isagi Y. 2016. Vertical structure of 681 phyllosphere fungal communities in a tropical forest in Thailand uncovered by high-

682 throughput sequencing. PLoS ONE 11: e0166669.

683 Jacquemyn H, Brys R, Lievens B, Wiegand T. 2012. Spatial variation in below-ground 684 seed germination and divergent mycorrhizal associations correlate with spatial segregation of 685 three co-occurring orchid species. Journal of Ecology 100: 1328-1337.

686 Jacquemyn H, Brys R, Merckx VSFT, Waud M, Lievens B, Wiegand T. 2014. Coexisting 687 orchid species have distinct mycorrhizal communities and display strong spatial segregation. 688 New Phytologist 202: 616-627.

689 Jacquemyn H, Duffy KJ, Selosse M-A. 2017. Biogeography of Orchid Mycorrhizas. In:

690 Tedersoo L, ed. Biogeography of Mycorrhizal Symbiosis, Ecological Studies 230, L.

691 Tedersoo (ed.). Springer International Publishing, Cham, Switzerland, 159-177.

692 Jacquemyn H, Rein B, Katrien V, Olivier H, Isabel R-R, Thorsten W. 2007. A spatially

693 of seedling recruitment in analysis explicit the terrestrial orchid Orchis purpurea. New

694 Phytologist 176: 448-459.

695 Kadowaki K, Sato H, Yamamoto S, Tanabe AS, Hidaka A, Toju H. 2014. Detection of

696 the horizontal spatial structure of soil fungal communities in a natural forest. Population

697 Ecology 56: 301-310.

698 Kartzinel TR, Trapnell DW, Shefferson RP. 2013. Critical importance of large native trees 699 for conservation of a rare neotropical epiphyte. Journal of Ecology 101: 1429-1438.

700 Kembel SW, Mueller RC. 2014. Plant traits and taxonomy drive host associations in tropical 701 Phyllosphere fungal communities1. Botany 92: 303-311.

702 Kottke I, Garnica S, Herrera P, Cruz D, Haug I, Suárez JP, Bauer R. 2010.

703 Atractiellomycetes belonging to the 'rust' lineage (Pucciniomycotina) form mycorrhizae with 704 terrestrial and epiphytic neotropical orchids. Proc. R. Soc. B 277: 1289-1298.

705 Lana LG, Escobar TF, Godinho EM, Peluzio LE. 2018. Survey of Orchidaceae species of 706 Serra das Cabeças, in Parque Estadual da Serra do Brigadeiro, Araponga-MG, Brazil.

707 Horticultura Brasileira 36: 156-166. 
Lehnert M, Krug M, Kessler M. 2017. A review of symbiotic fungal endophytes in lycophytes and ferns - a global phylogenetic and ecological perspective. Symbiosis 71: 77-89. Lekberg Y, Koide RT, Rohr JR, Aldrich-Wolfe L, Morton JB. 2007. Role of niche restrictions and dispersal in the composition of arbuscular mycorrhizal fungal communities. Journal of Ecology 95: 95-105.

Leroy C, Maes AQM, Louisanna E, Séjalon-Delmas N. 2019. How significant are endophytic fungi in bromeliad seeds and seedlings? Effects on germination, survival and performance of two epiphytic plant species. Fungal Ecology 39: 296-306.

Mahé F, Rognes T, Quince C, de Vargas C, Dunthorn M. 2015. Swarmv2: highly-scalable and high-resolution amplicon clustering. PeerJ 3:e1420.

Martin M. 2011. Cutadapt removes adapter sequences from high-throuoghput sequencing reads. EMBnet.journal 17: 10-12.

Martos F, Munoz F, Pailler T, Kottke I, Gonneau C, Selosse M-A. 2012. The role of epiphytism in architecture and evolutionary constraint within mycorrhizal networks of tropical orchids. Molecular Ecology 21: 5098-5109.

McCormick MK, Jacquemyn H. 2014. What constrains the distribution of orchid populations? New Phytologist 202: 392-400. McCormick MK, Taylor DL, Whigham DF, Burnett RK. 2016. Germination patterns in three terrestrial orchids relate to abundance of mycorrhizal fungi. Journal of Ecology 104: 744-754.

McCormick MK, Whigham DF, Canchani-Viruet A. 2018. Mycorrhizal fungi affect orchid distribution and population dynamics. New Phytologist 219: 1207-1215.

McKnight DT, Huerlimann R, Bower DS, Schwarzkopf L, Alford RA, Zenger KR. 2019. Methods for normalizing microbiome data: An ecological perspective. Methods in Ecology and Evolution 10: 389-400. Millar RB, Anderson MJ, Tolimieri N. 2011. Much ado about nothings: using zero similarity points in distance-decay curves. Ecology 92: 1717-1722. Morris PF, Bone E, Tyler BM. 1998. Chemotropic and contact responses of Phytophthora sojae hyphae to soybean isoflavonoids and artificial substrates. Plant Physiology 117: 11711178.

Mujic AB, Durall DM, Spatafora JW, Kennedy PG. 2016. Competitive avoidance not edaphic specialization drives vertical niche partitioning among sister species of ectomycorrhizal fungi. New Phytologist 209: 1174-1183. 
Porter TM, Bengtsson-Palme J, Walker DM, De Sousa F, et al. 2015. A comprehensive,

743

744

745

746

747

748

749

750

751

752

753

754

755

756

757

758

759

760

761

762

763

764

765

766

767

768

769

770

771

772

773

774

775 automatically updated fungal ITS sequence dataset for reference-based chimera control in environmental sequencing efforts. Microbes and Environments 30: 145-150.

Novotná A, Benítez Á, Herrera P, Cruz D, Filipczyková E, Suárez JP. 2018. High diversity of root-associated fungi isolated from three epiphytic orchids in southern Ecuador. Mycoscience 59: 24-32.

Oja J, Vahtra J, Bahram M, Kohout P, Kull T, Rannap R, Kõljalg U, Tedersoo L. 2016. Local-scale spatial structure and community composition of orchid mycorrhizal fungi in seminatural grasslands. Mycorrhiza 27: 355-367.

Oksanen J, F. Guillaume Blanchet RK, Legendre P, Minchin PR, O'Hara RB, Simpson GL, Solymos P, M. Henry H. Stevens HW. 2013. Vegan: Community Ecology Package. [WWWdocument] URL http://cran.r-project.org/package=vegan [access in February 2018]. Peay KG, Baraloto C, Fine PVA. 2013. Strong coupling of plant and fungal community structure across western Amazonian rainforests. ISME Journal 7: 1852-1861.

Pickles BJ, Genney DR, Potts JM, Lennon JJ, Anderson IC, Alexander IJ. 2010. Spatial and temporal ecology of Scots pine ectomycorrhizas. New Phytologist 186: 755-768.

Rasmussen HN, Rasmussen FN. 2018. The epiphytic habitat on a living host : reflections on the orchid - tree relationship. Botanical Journal of the Linnean Society 186: 456-472.

Rognes T, Flouri T, Nichols B, Quince C, Mahé F. 2016. VSEARCH: a versatile open source tool for metagenomics. PeerJ 4:e2584.

Rolim FA, Ribeiro GA. 2001. Levantamento do potencial turistico do parque estadual da Serra do Brigadeiro - PESB com o Suporte em Geoprocessamento.

Rowe AR, Pringle A. 2005. Morphological and molecular evidence of arbuscular mycorrhizal fungal associations in Costa Rican epiphytic bromeliads. Biotropica 37: 245250.

Sarmiento C, Zalamea PC, Dalling JW, Davis AS, Stump SM, U'Ren JM, Arnold AE. 2017. Soilborne fungi have host affinity and host-specific effects on seed germination and survival in a lowland tropical forest. PNAS 114: 11458-11463.

Schmidt PA, Bálint M, Greshake B, Bandow C, Römbke J, Schmitt I. 2013. Illumina metabarcoding of a soil fungal community. Soil Biology and Biochemistry 65: 128-132. Schneider-Maunoury L, Leclercq S, Clément C, Covès H, Lambourdière J, Sauve M, Richard F, Selosse MA, Taschen E. 2018. Is Tuber melanosporum colonizing the roots of herbaceous, non-ectomycorrhizal plants? Fungal Ecology 31: 59-68.

Selosse MA, Martos F. 2014. Do chlorophyllous orchids heterotrophically use mycorrhizal 
fungal carbon? Trends in Plant Science 19: 683-685.

777 Selosse MA, Schneider-Maunoury L, Martos F. 2018. Time to re-think fungal ecology?

778 Fungal ecological niches are often prejudged. New Phytologist 217: 968-972.

779 Sloan WT, Lunn M, Woodcock S, Head IM, Nee S, Curtis TP. 2006. Quantifying the roles 780 of immigration and chance in shaping prokaryote community structure. Environmental 781 Microbiology 8: 732-740.

782 Smith SE, Read DJ. 2008. Mycorrhizal Symbiosis. Cambridge, Great Britain: Elsevier Ltd., 7832008.

784 Spatafora JW, Aime MC, Grigoriev I V., Martin F, Stajich JE, Blackwell M. 2017. The 785 fungal tree of life: from molecular systematics to genome-scale phylogenies. Microbiology 786 Spectrum 5: 3-34.

787 Sun YP, Fries N. 1992. The effect of tree-root exudates on the growth rate of 788 ectomycorrhizal and saprotrophic fungi. Mycorrhiza 1: 63-69.

789 Taylor DL, McCormick MK. 2008. Internal transcribed spacer primers and sequences for 790 improved characterization of basidiomycetous orchid mycorrhizas. New Phytologist 177: $791 \quad 1020-1033$.

792 Tedersoo L, Anslan S, Bahram M, Põlme S, Riit T, Liiv I, Kõljalg U, Kisand V, Nilsson 793 RH, Hildebrand F, et al. 2015. Shotgun metagenomes and multiple primer pair-barcode 794 combinations of amplicons reveal biases in metabarcoding analyses of fungi. MycoKeys $\mathbf{1 0}$ : $795 \quad 1-43$.

796 Tedersoo L, Sadam A, Zambrano M, Valencia R, Bahram M. 2010. Low diversity and 797 high host preference of ectomycorrhizal fungi in Western Amazonia, a neotropical 798 biodiversity hotspot. ISME Journal 4: 465-471.

799 Toju H, Tanabe AS, Ishii HS. 2016. Ericaceous plant-fungus network in a harsh alpine800 subalpine environment. Molecular Ecology 25: 3242-3257.

801 Turenne CY, Sanche SE, Hoban DJ, Karlowsky JA, Kabani AM. 1999. Rapid

802 identification of fungi by using the ITS2 genetic region and an automated fluorescent 803 capillary electrophoresis system. Journal of Clinical Microbiology 37: 1846-1851.

804 Vacher C, Cordier T, Vallance J. 2016. Phyllosphere fungal communities differentiate more 805 thoroughly than bacterial communities along an elevation gradient. Microbial Ecology 72: 18063.

807 Veldre V, Abarenkov K, Bahram M, Martos F, Selosse M-A, Tamm H, Kõljalg U, 808 Tedersoo L. 2013. Evolution of nutritional modes of Ceratobasidiaceae (Cantharellales, 809 Basidiomycota) as revealed from publicly available ITS sequences. Fungal Ecology 6: 256- 
268.

811 Venkataraman A, Bassis CM, Beck JM, Young VB, Curtis JL, Huffnagle GB, Schmidt

812 TM. 2015. Application of a neutral community model to assess structuring of the human lung 813 microbiome. mBio 6: 1-9.

814 Voyron S, Ercole E, Ghignone S, Perotto S, Girlanda M. 2017. Fine-scale spatial

815 distribution of orchid mycorrhizal fungi in the soil of host-rich grasslands. New Phytologist

816 213: 1428-1439.

817 Waud M, Busschaert P, Lievens B, Jacquemyn H. 2016a. Specificity and localised

818 distribution of mycorrhizal fungi in the soil may contribute to co-existence of orchid species.

819 Fungal Ecology 20: 155-165.

820 Waud M, Wiegand T, Brys R, Lievens B, Jacquemyn H. 2016b. Nonrandom seedling

821 establishment corresponds with distance-dependent decline in mycorrhizal abundance in two

822 terrestrial orchids. New Phytologist 211: 255-264.

823 Weiß M, Waller F, Zuccaro A, Selosse M-A. 2016. Sebacinales - one thousand and one 824 interactions with land plants. New Phytologist 211: 20-40.

825 Whitcomb S, Stutz JC. 2007. Assessing diversity of arbuscular mycorrhizal fungi in a local 826 community: role of sampling effort and spatial heterogeneity. Mycorrhiza 17: 429-437.

827 White TJ, Bruns T, Lee S, Taylor J. 1990. Amplification and direct sequencing of fungal 828 ribosomal RNA genes fr phylogenetics. In: Innis MA, Gelfand DH, Shinsky JJ, White TJ, eds. 829 PCR Protocols : A Guide to Methods and Applications. London, Great Britain: Academic 830 Press, $315-322$.

831 Wilson EB. 1927. Probable inference, the law of succession, and statistical inference. Journal 832 of the American Statistical Association 22: 209-212.

833 Xing X, Jacquemyn H, Gai X, Gao Y, Liu Q, Zhao Z, Guo S. 2019. The impact of life 834 form on the architecture of orchid mycorrhizal networks in tropical forest. Oikos 128: 12548351264.

836 Yang RH, Su JH, Shang JJ, Wu YY, Li Y, Bao DP, Yao YJ. 2018. Evaluation of the 837 ribosomal DNA internal transcribed spacer (ITS), specifically ITS1 and ITS2, for the analysis 838 of fungal diversity by deep sequencing. PLoS ONE 13: 1-17.

839 Yoder JA, Imfeld SM, Heydinger DJ, Hart CE, Collier MH, Gribbins KM, Zettler LW. 840 2010. Comparative water balance profiles of Orchidaceae seeds for epiphytic and terrestrial 841 taxa endemic to North America. Plant Ecology 211: 7-17.

842 Zanne AE, Abarenkov K, Afkhami ME, Aguilar-Trigueros CA, Bates S, Bhatnagar JM, 843 Busby PE, Christian N, Cornwell WK, Crowther TW, et al. 2019. Fungal functional 
844 ecology: bringing a trait-based approach to plant-associated fungi. Biological Reviews 95:

$845 \quad 409-433$.

846 Zhang K, Adams JM, Shi Y, Yang T, Sun R, He D, Ni Y, Chu H. 2017. Environment and

847 geographic distance differ in relative importance for determining fungal community of

848 rhizosphere and bulk soil. Environmental Microbiology 19: 3649-3659.

849 Zinger L, Bonin A, Alsos IG, Bálint M, Bik H, Boyer F, Chariton AA, Creer S, Coissac

850 E, Deagle BE, et al. 2019. DNA metabarcoding - Need for robust experimental designs to

851 draw sound ecological conclusions. Molecular Ecology 28: 1857-1862.

852 Zotz G. 2016. Plants on Plants - The Biology of Vascular Epiphytes. Heidelberg, Berlin,

853 Germany: Springer International Publishing, 2016.

854

855

856 Supporting Information

857 Fig. S1: Sampling design of tree 2.

858 Fig. S2: Rarefaction curves.

859 Fig. S3: Global fungal composition.

860 Fig. S4: Application of Neutral Community Model (NCM) to fungal endophytes.

861 Fig. S5: OTUs deviation from Neutral Community Model (NCM).

862 Fig. S6: Fungal guilds deviation from Neutral Community Model (NCM)

863 Fig. S7: NMDS on total fungal community, considering root samples only.

864 Fig. S8: Turnover of fungal community on vertical versus horizontal axis.

865 Fig. S9: Vertical density distribution of OMF families.

866 Fig. S10: Distance-decay of similarity from roots for other fungal guilds.

867 Fig. S11: Density distribution of OMF at a distance from roots.

868 Fig. S12: Distance-decay of bark richness from roots for total fungal community.

869 Fig. S13: Distance-decay of bark richness from roots for OMF community.

870 Fig. S14: Distance-decay of bark richness from roots for other fungal guilds.

871 Table S1: Details of the sampling depth.

872 Table S2: Global fungal composition.

873 Table S3: Fungal composition at family and genera levels (.xlsx file).

874 Table S4: Number of OTUs shared between roots and bark compartments in each grid.

875 Table S5: OMF composition of orchid roots (.xlsx file).

876 Table S6: Spatial autocorrelation of OTUs.

877 Table S7: Spatial autocorrelation of richness based on Moran calculation. 
878 Table S8: GLM result parameters for distance-decay of similarity.

879 Table S9: ANOVA results for distance-decay of bark richness from roots.

880

881

882

883

884

885

886

887

888

889

890

891

892

893

894

895

896

897

898

899

900

901

902

903

904

905

906

907

908

909

910 
911 Table 1. General spatial features for each fungal guild. The number of OTUs in each guild is

912 given prior to rarefaction. Mantel $\mathrm{R}$ index and Sim. Dec. $\beta$ slope (slope of similarity decay

913 between bark and roots, based on Jaccard index, and associated r value for Mantel test; see

914 Table S6 for details) are calculated after rarefaction. ${ }^{*} \mathrm{p}<0.05,{ }^{*} \mathrm{p}<0.01, * * * \mathrm{p}<0.001$, n.s,

915 non-significant.

916

\begin{tabular}{|c|c|c|c|c|}
\hline Guild & Grid & Number OTUs & Mantel R & Sim. Dec. $\beta$ slope ; $\mathbf{r}$ \\
\hline \multirow[t]{2}{*}{ Total } & 1 & 2445 & $0.238 * * *$ & $0.013 ; 0.231^{*}$ \\
\hline & 2 & 3724 & $0.215 * * *$ & $0.004 ; 0.235^{* * *}$ \\
\hline \multirow[t]{2}{*}{ Endophyte } & 1 & 1816 & $0.234 * * *$ & $0.012 ; 0.201 *$ \\
\hline & 2 & 3233 & $0.191 * * *$ & $0.004 ; 0.235^{* * *}$ \\
\hline \multirow[t]{2}{*}{ OMF } & 1 & 14 & $0.206^{* * *}$ & $0.005 ;-0.291^{\mathrm{n} . \mathrm{s}}$ \\
\hline & 2 & 31 & $0.560 * * *$ & $0.035 ; 0.604 * * *$ \\
\hline \multirow[t]{2}{*}{ Lichenized } & 1 & 196 & $0.005^{\mathrm{ns}}$ & $0.043 ; 0.123^{\mathrm{ns}}$ \\
\hline & 2 & 263 & $0.072 * *$ & $0.006 ; 0.032^{\mathrm{ns}}$ \\
\hline \multirow[t]{2}{*}{ Plant Pathogen } & 1 & 333 & $0.098 * *$ & $0.013 ; 0.012^{\mathrm{ns}}$ \\
\hline & 2 & 493 & $0.091 * *$ & $0.002 ; 0.144^{* *}$ \\
\hline \multirow[t]{2}{*}{ Saprotroph } & 1 & 637 & $0.125 * *$ & $-0.002 ; 0.082^{\mathrm{ns}}$ \\
\hline & 2 & 956 & $0.070 * *$ & $0.002 ; 0.092 *$ \\
\hline \multirow[t]{2}{*}{ Symbiotroph } & 1 & 26 & $-0.005^{\mathrm{ns}}$ & $0.009 ; 0.392 *$ \\
\hline & 2 & 55 & $0.094^{\mathrm{ns}}$ & $0.003 ;-0.041^{\mathrm{ns}}$ \\
\hline
\end{tabular}

917

918

919

920

921

922 
923 Figure 1. Sampling design of tree 1. (A) Sampling design of the first tree (Siparuna sp.)

924 containing five individuals of the epiphytic orchid Isochilus linearis (orange, 1-5). Bark was 925 sampled regularly (black filled circles) along the grid, and additionally several points were 926 randomly sampled around orchid individuals 1 and 4 (black filled stars). The grid covered the 927 whole circumference of the tree, and grey filled circles indicate the position of sampling points 928 from the opposite side of the grid (e.g. points designated by an arrow are at the same position 929 on the trunk). Orchid roots were regularly sampled along each root (orange filled rectangles). 930 The picture (B) shows a detail of orchid individual 3 before sampling, showing that orchid roots 931 were easily traceable along the trunk, allowing precise spatial analyses. Scale: $3 \mathrm{~cm}$. The 932 sampling design of tree 2 is presented in Fig. S1.

933

A

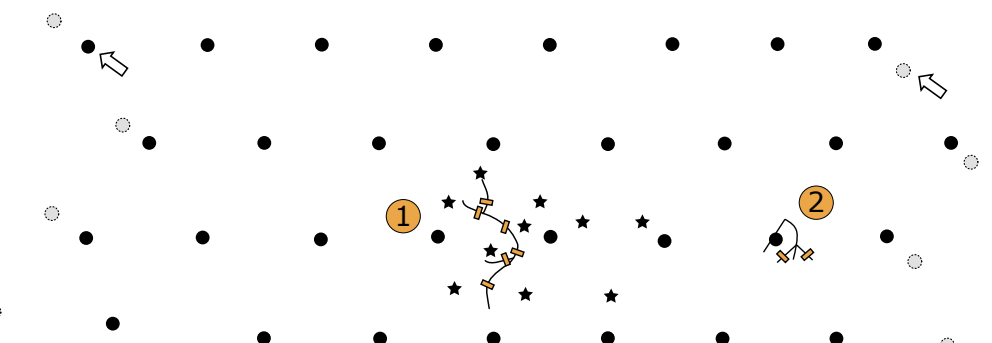

934

935

936

937

938

939

940

941
B

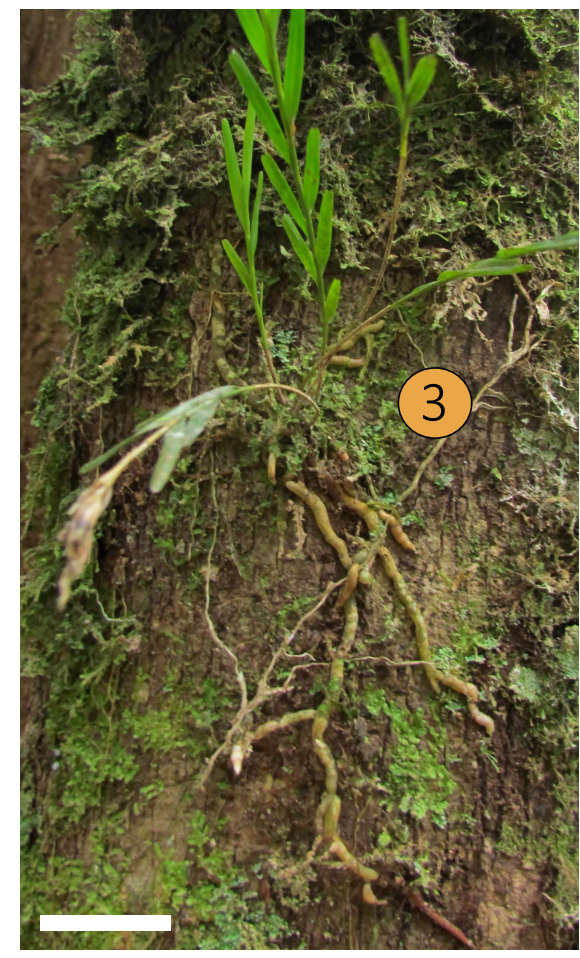


942 Figure 2. Non-metric multidimensional scaling (NMDS) on total fungal community,

943

944

945

946

947

948

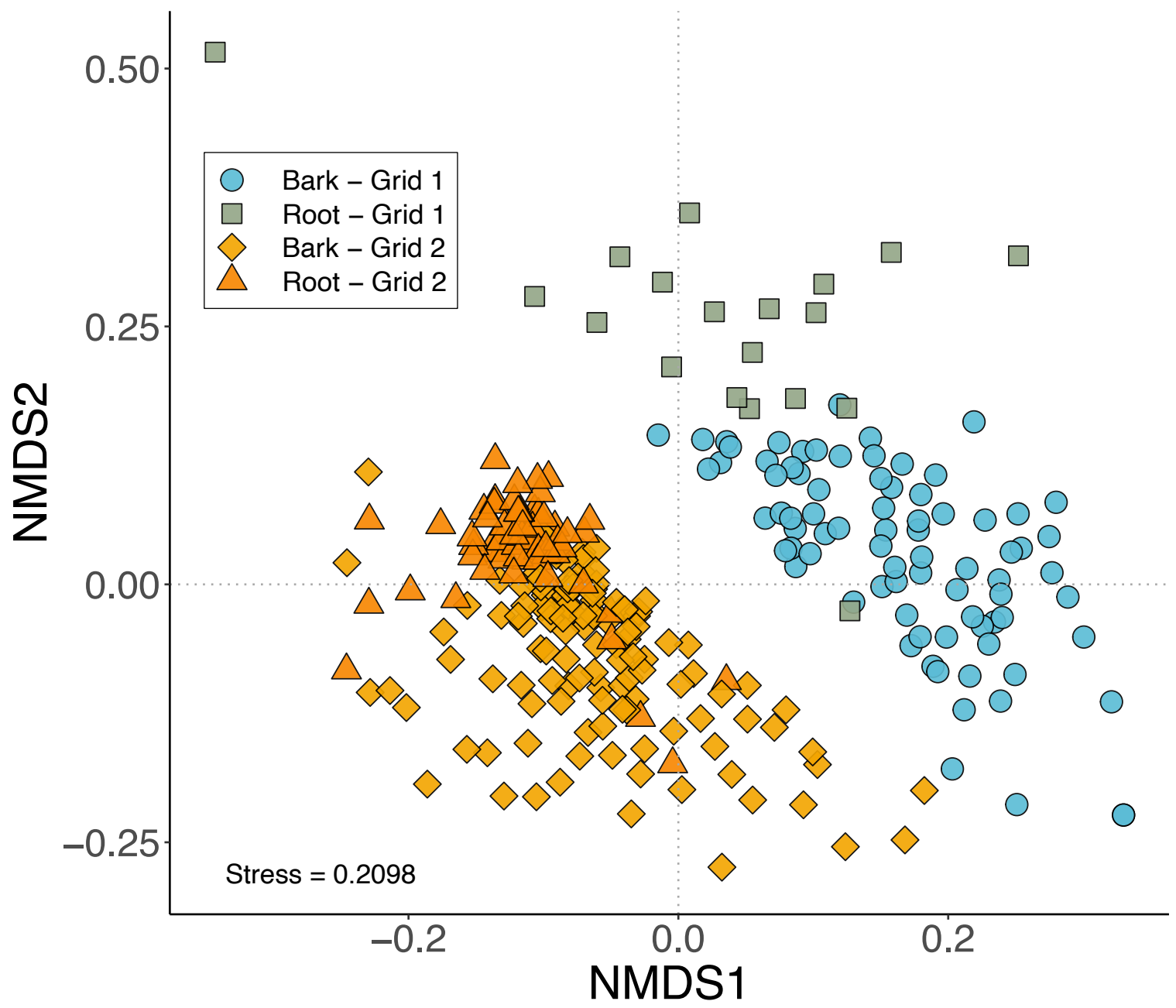

949

950

951

952

953

954

955 
957 roots. Bars show the cumulative proportion of sequences (in \%) for each OTU in each orchid 958 individual. One Isochilus linearis individual on grid 1 has been removed because of the absence 959 of detected OMF in its roots. Bar colors indicate the OTU family. The number of samples 960 available for each individual ( $\mathrm{N}_{\text {samples}}$ ) as well as the number of OMF OTUs (NotUs) found in 961 them are given above each bar. The orchid individual numbers at the bottom of the graph refer 962 to the sampling designs illustrated in Fig. 1 and Fig. S1. See Table S5 for further details 963 concerning these communities. I. linearis: Isochilus linearis; E. armeniacum: Epidendrum 964 armeniacum.

965

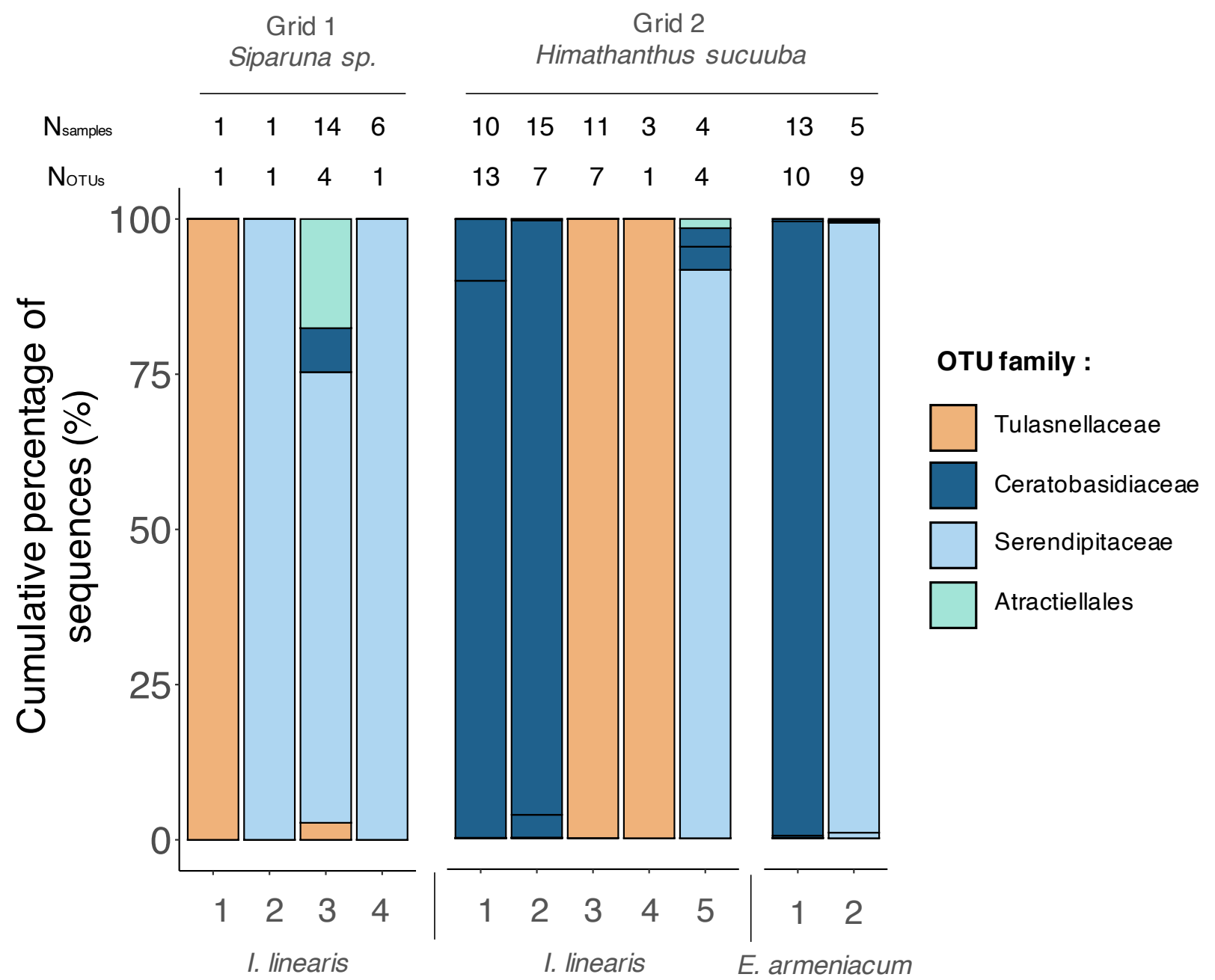


972 Figure 4. Spatial autocorrelation of fungal community composition. Mantel correlograms

973 show spatial autocorrelation based on presence/absence of (A-B) total fungal community,

974 fungal endophytes and orchid mycorrhizal fungi (OMF) and (C-D) lichenized, plant pathogen,

975 saprotroph and symbiotroph fungal guilds (Jaccard index) for (A and C) grid 1 and (B and D)

976 grid 2. A positive value corresponds to a positive autocorrelation and conversely. Filled circles

977 indicate a significant value. Thick lines in the bottom of each graph indicate the distance of

978 significant spatial autocorrelation for each guild represented. Total and endophyte curves are 979 confounded on panel B.

980

A
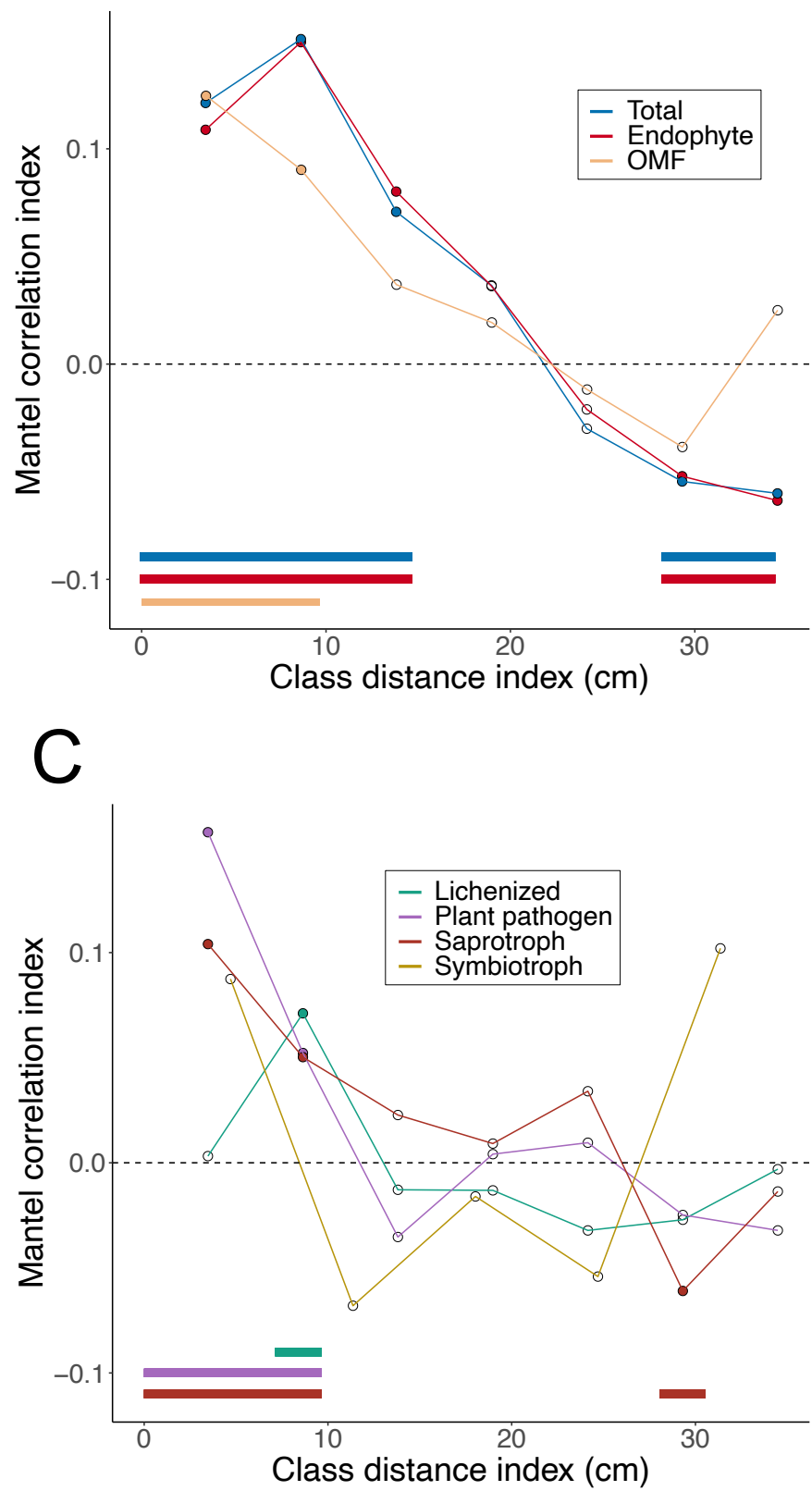

B
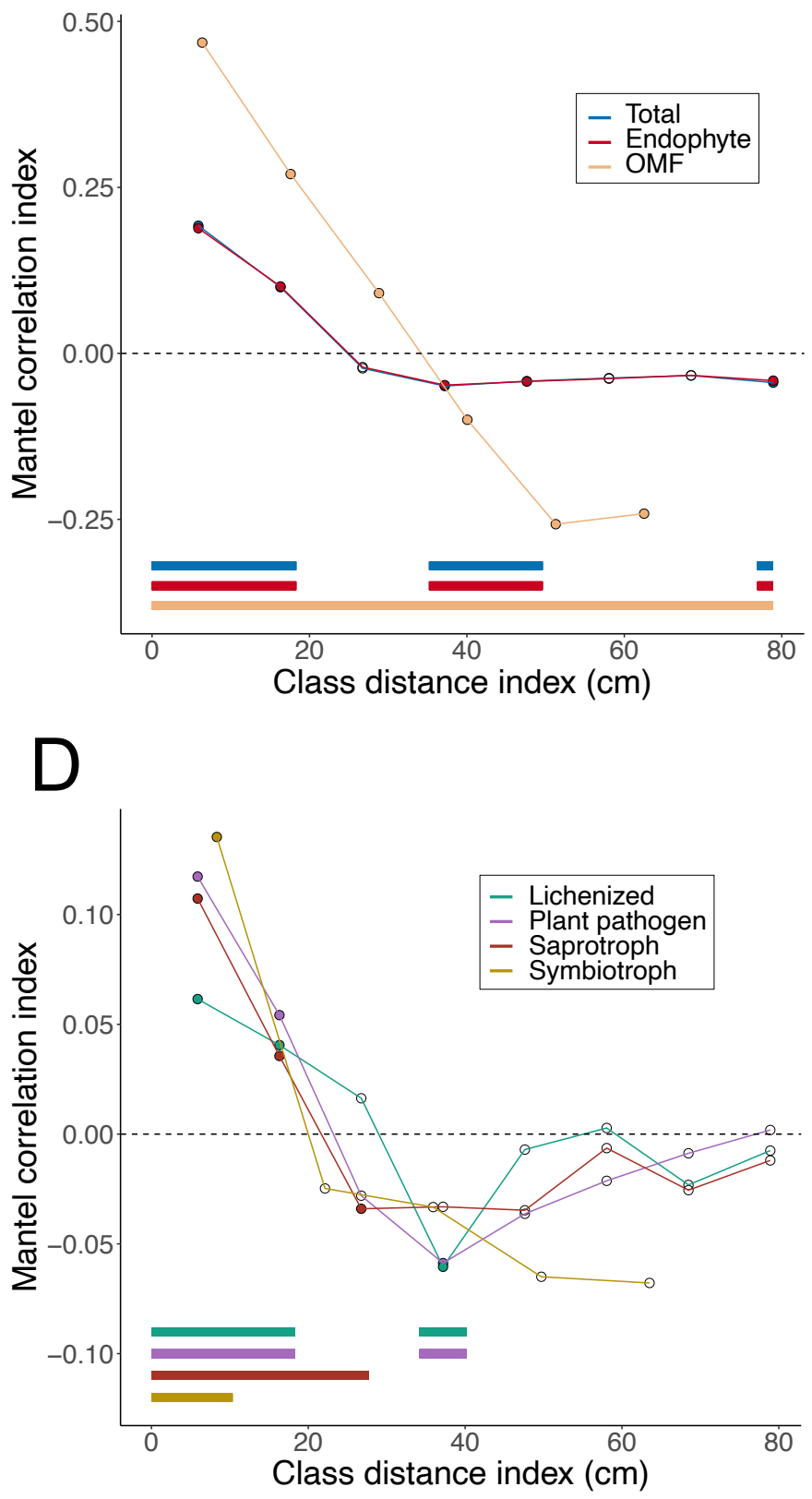
981 Figure 5. Distance-decay of similarity (based on Jaccard index) between roots and bark for 982 total (large panel, blue) and orchid mycorrhizal fungi (OMF; small panel, orange) communities 983 for (A) grid 1 and (B) grid 2. Colored lines show the regressions of a binomial GLM (log link 984 function) and the colored areas represent the associated $95 \%$ confidence interval. A significant 985 tendency (Mantel test) is indicated by an asterisk (* p $<0.05$, *** $\mathrm{p}<0.001$, n.s, non986 significant). See Table S8 for details.
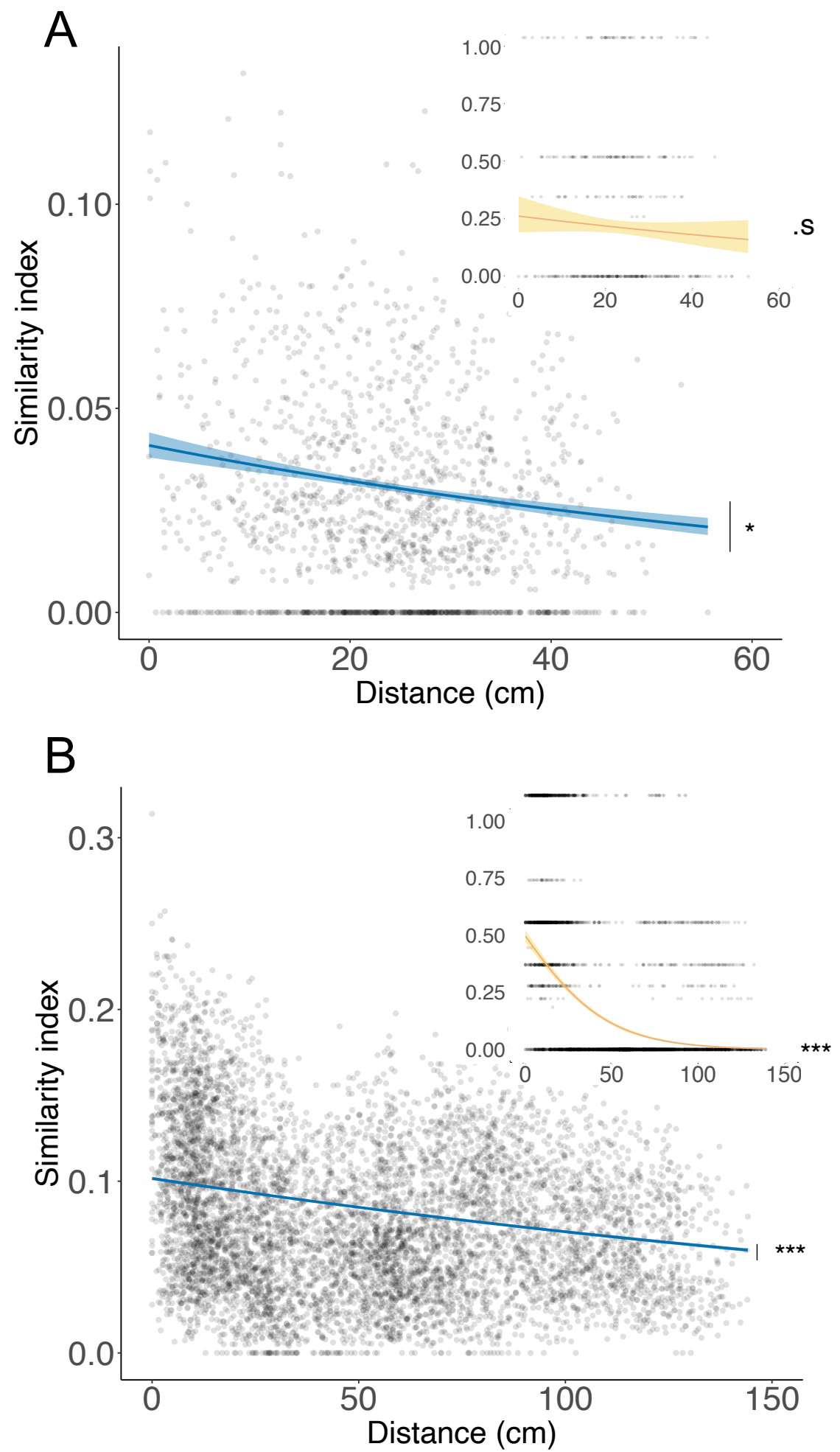